\title{
RECURSOS PEDAGÓGICOS NO DESENVOLVIMENTO EDUCACIONAL DA CRIANÇA SURDA
}

\author{
Maria José Siqueira de Souza \\ Universidade Federal do Amazonas \\ orcid.org/0000-0003-2958-6677 \\ mjsdesouzaa@gmail.com \\ Danilza de Souza Teixeira \\ Universidade Federal do Amazonas \\ orcid.org/0000-0002-9098-8766 \\ danilzast1@gmail.com \\ Jadson Justi \\ Universidade Federal do Amazonas \\ orcid.org/0000-0003-4280-8502 \\ jadsonjusti@hotmail.com
}

Para citar este artículo puede utilizar el siguiente formato:

Maria José Siqueira de Souza, Danilza de Souza Teixeira y Jadson Justi: "Recursos pedagógicos no desenvolvimento educacional da criança surda", Revista Atlante: Cuadernos de Educación y Desarrollo, ISSN: 1989-4155 (vol 13, № 6 julio-septiembre 2021, pp. 44-63). En línea:

https://doi.org/10.51896/atlante/PSKY5941

\section{RESUMO}

Este estudo justifica a necessidade de se refletir o processo educacional mediado por materiais pedagógicos diante da surdez. O objetivo desta pesquisa é descrever possíveis influências de recursos pedagógicos no desenvolvimento educacional de uma aluna surda do ensino fundamental. A metodologia adotada é descritiva com abordagem qualitativa. Utilizaram-se como coleta de dados, a observação assistemática e entrevista com três docentes do ensino fundamental que lecionam para uma aluna com surdez em uma escola situada em Parintins, Amazonas, Brasil. Os resultados apontam fortes evidências positivas na aprendizagem da aluna surda devidamente influenciadas por materiais pedagógicos e ambiente socializador escolar. Conclui-se que os recursos didáticopedagógicos utilizados são essenciais para a alfabetização e o letramento, e as tecnologias da informação e comunicação são ferramentas que integram, estimulam e influenciam aspectos pessoais, sociais e educacionais de alunos surdos e ouvintes concomitantemente.

Palavras-chave: Recursos pedagógicos, Aprendizagem escolar, Aluno surdo.

\section{RECURSOS PEDAGÓGICOS SOBRE EL DESARROLLO EDUCATIVO DEL NIÑO SORDO}

\section{RESUMEM}

Este estudio justifica la necesidad de reflexionar sobre el proceso educativo mediado por materiales 
didácticos para estudiantes sordos. El objetivo de esta investigación es describir las posibles influencias de los recursos pedagógicos en el desarrollo educativo de un estudiante sordo. La metodología adoptada es descriptiva con un enfoque cualitativo. Como una recopilación de datos, se utilizaron observaciones y entrevistas no sistemáticas con tres maestros que enseñan a un estudiante con sordera en una escuela ubicada en Parintins, Amazonas, Brasil. Los resultados apuntan a una fuerte evidencia positiva en el aprendizaje de los estudiantes sordos, debidamente influenciados por los materiales de enseñanza y un entorno socializador. Se concluye que los recursos didácticopedagógicos utilizados son esenciales para el desarrollo, y las tecnologías de la información y la comunicación son herramientas que estimulan e influyen simultáneamente en los aspectos personales, sociales y educativos de los estudiantes sordos y oyentes.

Palabras clave: Recursos pedagógicos, Aprendizaje escolar, Estudiante sordo.

\section{PEDAGOGICAL RESOURCES ON THE EDUCATIONAL DEVELOPMENT OF THE DEAF CHILD}

\section{ABSTRACT}

This study justifies the need to reflect on the educational process mediated by teaching materials in the face of deafness. The objective of this research is to describe possible influences of pedagogical resources on the educational development of a deaf student. The methodology adopted is descriptive with a qualitative approach. As a data collection, unsystematic observation and interview with three teachers who teach to a student with deafness in a school located in Parintins, Amazonas, Brazil were used. The results point to strong positive evidence in deaf student learning, duly influenced by teaching materials and a socializing environment. It is concluded that the didactic-pedagogical resources used are essential for development, and the information and communication technologies are tools that stimulate and influence personal, social and educational aspects of deaf and hearing students simultaneously.

Keywords: Pedagogical resources, School learning, Deaf student.

\section{INTRODUÇÃO}

A realização deste estudo deu-se com o objetivo de descrever possíveis influências de recursos pedagógicos no desenvolvimento educacional de uma aluna surda do ensino fundamental. Para tanto, essa pesquisa delimita-se em uma lógica educacional, haja vista que leva em sua essência a realidade de alunos surdos na condição escolar. Logo, crianças com ou sem deficiência têm o direito educacional com qualidade e as necessidades específicas devem ser trabalhadas para que o seu desenvolvimento multidimensional seja atingido. A influência dos recursos pedagógicos utilizados em sala de aula pode levar ao desenvolvimento ou não do aluno. Esclarece-se, ainda, que neste estudo compreende-se os termos material e recurso pedagógico como sinônimos.

O uso de recursos pedagógicos na aprendizagem de alunos em fase inicial de escolarização é um fator que pode interferir diretamente em seu ensino, pois eles complementam e auxiliam o trabalho do professor em favor da educação dos alunos, dando base para a compreensão dos 
conteúdos explorados no espaço educacional. Assim, problematiza-se este estudo com a questão: quais as possíveis influências de recursos pedagógicos no desenvolvimento educacional da criança surda?

\section{Comunicação humana}

As línguas utilizadas pelas pessoas são essenciais para que haja a interação e comunicação com o outro, para que assim todos possam socializar-se e manter um bom convívio em sociedade na qual estão inseridos (Silva y Martins, 2020; Woodward, 1972).

Desde épocas remotas, o ser humano sente a necessidade de se comunicar com o outro, como: para a caça, se proteger de predadores, de questões climáticas, entre outros fatores, decorrendo à época em que se encontrava. A partir da necessidade humana de sobrevivência, a comunicação foi evoluindo e se dividindo entre as nações do mundo por meio das diversas linguagens existentes, inclusive a linguagem oral.

A comunicação dos seres humanos é fundamentalmente diferente e superior as demais formas de comunicação conhecidas. Os humanos nascem com os mecanismos da linguagem específicos da espécie, e todos normalmente os desenvolvem, não dependente de qualquer fator racial, social ou cultural (Sánchez, 1990).

A comunicação por meio da fala é predominante em todas as nações do mundo, pois a parte majoritária das pessoas são ouvintes, e a parte minoritária são pessoas surdas que se comunicam por meio das línguas de sinais pertencentes a uma determinada nacionalidade (Lane, 1992). "As línguas expressam a capacidade específica dos seres humanos para a linguagem, expressam as culturas, os valores e os padrões sociais de um determinado grupo social" (Quadros y Schmiedt, 2006, p. 13)

\section{Considerações sobre Língua Brasileira de Sinais na condição de primeira língua}

A Língua Brasileira de Sinais (LIBRAS) é a língua materna dos surdos brasileiros e a língua portuguesa é utilizada na modalidade escrita (Almeida y Lacerda, 2019; Lodi, 2013a, 2013b). Essas línguas trazem uma bagagem de informações para os surdos terem acesso e direito à comunicação sem restrição ao conhecimento (Ferreira, 2010; Lodi et al., 2004). Partindo dessa lógica, a abordagem bilíngue aponta a língua de sinais como primeira língua dos surdos também chamada de L1, e como segunda língua chamada de L2, aquela que é a oficial do país, no caso do Brasil, a língua portuguesa. Desta forma, garante-se a pessoa, o desenvolvimento de sua linguagem e a construção de conceitos essenciais para a leitura de mundo, pois depende da língua para alicerçar esses aprendizados (Agria y Vieira, 2013).

A LIBRAS foi reconhecida pela Lei n. 10.43624 de abril de 2002 (2002), que diz,

Art. $1^{0}$ É reconhecida como meio legal de comunicação e expressão a Língua Brasileira de Sinais - Libras e outros recursos de expressão a ela associados. 
Parágrafo único. Entende-se como Língua Brasileira de Sinais - Libras a forma de comunicação e expressão, em que o sistema lingüístico [sic] de natureza visual-motora, com estrutura gramatical própria, constituem um sistema lingüístico [sic] de transmissão de idéias [sic] e fatos, oriundos de comunidades de pessoas surdas do Brasil.

Essa Lei reconhece legalmente os direitos aos surdos terem uma língua própria para a comunicação e expressão em território brasileiro, mas não substituindo a língua portuguesa na modalidade escrita, para garantir sua cidadania (Silva y Justi, 2018).

O Decreto n. 5.626 de 22 de dezembro de 2005 (2005), regulamenta a Lei n. 10.436/2002, garantindo o acesso à educação dos surdos desde a Educação Infantil ao Ensino Superior:

Art. 14. As instituições federais de ensino devem garantir, obrigatoriamente, às pessoas surdas acesso à comunicação, à informação e à educação nos processos seletivos, nas atividades e nos conteúdos curriculares desenvolvidos em todos os níveis, etapas e modalidades de educação, desde a educação infantil até à superior.

Desta forma, garante-se às pessoas surdas, também chamadas de deficientes auditivas, o acompanhamento por profissionais capacitados na formação na área da língua portuguesa e LIBRAS. A fim de ser oferecida uma educação bilíngue para que ocorra um pleno desenvolvimento educacional (Fernandes y Moreira, 2009; Thoma, 2016).

No entanto, muitas pessoas ouvintes não aceitam a LIBRAS como língua, visto que existem mais ouvintes do que surdos, e, sendo assim,

a maioria ouvinte utiliza uma língua na modalidade oral-auditiva, os surdos utilizam uma língua de modalidade visual-motora, com estrutura e gramática próprias. Entretanto, ela ainda não é valorizada como tal, e muitas vezes têm seu status de língua questionado (Agria y Vieira, 2013, p. 108).

Esse questionamento é por causa de a língua portuguesa que o surdo compreende (em uma lógica estrutural em LIBRAS) ser diferente do português do ouvinte, quando é escrita, sua estrutura gramatical não é como a dos ouvintes. Os surdos utilizam a escrita de acordo com a sinalização, pois, para eles, o entendimento acontece na lógica sintática e semântica que ocorre na comunicação em LIBRAS.

A LIBRAS na condição de primeira língua deve ser aprendida de forma natural pelos estudantes surdos, e as metodologias apresentadas devem ser de acordo com a necessidade e o nível de aprendizado que os alunos já apresentam sobre a língua de sinais (Fernandes y Moreira, 2014). Deve ser realizada em ambiente no qual os alunos possam interagir, brincar, correr, perguntar, entre outros (Lacerda et al., 2013; Lodi, 2013a, 2013b). Segundo Lacerda e Santos (2012), "a língua 
estará em funcionamento pela necessidade de os interlocutores interagirem e não em função de realizar exercícios ou treinamentos previamente organizados para aprender 'LIBRAS'" ou seja, quanto mais livre os alunos estiverem para se expressarem no desenvolvimento das aulas de LIBRAS melhor para os seus aprendizados no campo educacional e social (p. 141).

\section{Considerações sobre a língua portuguesa na condição de segunda língua}

A partir dos conhecimentos obtidos com a língua com a qual se identifica (primeira língua), o aluno surdo consegue relacionar os sinais para o português, pois a apropriação de sua língua o auxilia a fazer essa relação de forma mais harmoniosa (Felipe, 2007; Mota, 2008; Senna, 2019). Já a aquisição de segunda língua depende de como se configurou o processo linguístico de aquisição da primeira língua do aluno surdo. Quadros (1997) menciona que

A L1 é essencial - as crianças surdas precisam ter acesso a uma língua de sinais para garantir o desenvolvimento da linguagem e, consequentemente, do pensamento - e a L2 é necessária - as crianças precisam dominar a L2 para fazer valer os seus direitos diante da sociedade ouvinte (p. 85).

O trabalho pedagógico com imagens representativas dos objetos é essencial para a aquisição da língua portuguesa na modalidade escrita. Segundo Rafaeli e Silveira (2009), "Os ouvintes se alfabetizam pelo som, porém as crianças surdas se alfabetizam pelo visual; elas precisam representar pela escrita sua fala, que é a língua de sinais, que possui características visuo-espaciais" (p. 9).

Segundo Quadros e Schmiedt (2006),

Configurações de mão, movimentos, expressões faciais gramaticais, localizações, movimentos do corpo, espaço de sinalização, classificadores são alguns dos recursos discursivos que tal língua oferece para serem explorados durante o desenvolvimento da criança surda e que devem ser explorados para um processo de alfabetização com êxito (p. 26).

Deve-se ter o cuidado com o ensino da segunda língua, pois "A criança surda é colocada em contato com escrita do português para ser alfabetizada seguindo os mesmos passos e materiais utilizados nas escolas com as crianças falantes do português" (Quadros y Schmiedt, 2006, p. 23). Esse processo, muitas vezes, torna-se insignificante para alunos surdos, por não conseguirem corresponder às expectativas que os professores esperam em seu desenvolvimento na escrita da língua portuguesa (Bomfim y Souza, 2010; Sousa, 2018). Os materiais utilizados para os alunos surdos devem ser adaptados em LIBRAS, além do acompanhamento para que o aluno tenha acesso e compreensão eficaz ao que está sendo abordado nos conteúdos (Ellis, 1997; Galasso et al., 2018).

A segunda língua representa os significados (em paralelo a sua língua primária) para os alunos surdos em uma realidade de maioria ouvinte (Fernandes y Moreira, 2014; Nascimento y 
Costa, 2014; Vieira, 2017). Sem a aquisição dessa língua, os surdos sentem-se isolados na sociedade na qual vivem, e referente ao ensino, "o processo não pode e não deve ser puramente mecânico ele deve ser compreendido como um processo complexo, que envolve um indivíduo que pensa e necessita desenvolver ferramentas de integração e convivência na sociedade" (Rafaeli y Silveira, 2009, p. 10).

Menciona-se, ainda, que as peculiaridades do aluno surdo devem ser sempre respeitadas e levadas em consideração no momento do aprendizado da segunda língua (Barros et al., 2017; Lacerda et al., 2013). No decorrer do ensino da língua portuguesa, os professores devem explorar com seus alunos cada situação e questionamentos que lhes apresentados a fim de que não se passem despercebidas compreensões equivocadas no que tange às nuances entre primeira $e$ segunda língua por parte dos alunos surdos (Avelar y Freitas, 2016; Fernandes y Moreira, 2009; Nascimento y Costa, 2014).

\section{Bilinguismo no ambiente escolar}

A educação bilíngue é oferecida quando as políticas pedagógicas da escola entram em um acordo para a permissão da utilização de duas línguas a serem oferecidas no ambiente de ensino (Mota, 2008; Nascimento y Costa, 2014). No entanto, geralmente isso ocorre em escolas nas quais os alunos surdos obtêm o contato com a aprendizagem da língua de sinais e a língua portuguesa na modalidade escrita, concomitantemente (Sousa, 2018).

"A abordagem educacional por meio do bilinguismo visa capacitar a pessoa com surdez para a utilização de duas línguas no cotidiano escolar e na vida social, quais sejam: a língua de sinais e a língua da comunidade ouvinte" (Alvez et al., 2010, p. 7). Já Quadros (1997) afirma que o bilinguismo é uma proposta educacional utilizada por escolas que apresentam uma perspectiva acessível à criança de duas línguas no ambiente escolar.

Muitas crianças não aprendem a LIBRAS por terem nascido em famílias ouvintes que por algum motivo negam esse aprendizado para a criança (Teixeira et al., 2020). Desta forma, acabam se comunicando com gestos aleatórios que não fazem parte da convenção linguística de língua de sinais oficial brasileira, o que, de certa forma, não favorece em nada os processos comunicacionais (Ferreira, 2010; Mota, 2008). Para Rafaeli e Silveira (2009), a criança surda que não participar da comunidade de surdos, bem como da cultura que envolve a comunidade surda, poderá ter defasagens em sua linguagem de forma irreversível, não garantindo uma identidade surda nem de ouvintes.

É no momento do contato com o ambiente escolar que a criança surda tende a ter o conhecimento de uma língua no qual se identifica de forma consistente (Bomfim y Souza, 2010; Oliveira et al., 2019; Williams y Hammarberg, 1998). Assim, é nesse contexto de descobrimento de língua que as crianças surdas se desenvolvem e são estimuladas, correspondendo à comunicação com outras pessoas, havendo, portanto, o aprendizado significativo (Agria y Vieira, 2013; Borges et al., 2017).

Partindo dessa lógica, o uso da LIBRAS quanto do português escrito no processo de 
alfabetização e letramento deve ser de total responsabilidade e compromisso com a educação do aluno surdo, para que ele tenha avanços significativos nas múltiplas dimensões humanas (Avelar y Freitas, 2016; Fernandes y Moreira, 2009; Sousa, 2018). Tal compromisso proporciona subsídio para a integração do surdo em sociedade onde a expressão e a liberdade fornecidas pelo conhecimento são parte essencial para a construção de um caminho menos desigual (Justi et al., 2017).

\section{Considerações sobre recursos pedagógicos}

Os recursos didático-pedagógicos são utilizados no auxílio e/ou apoio ao professor no seu cotidiano laborativo para que a criança tenha mais entendimento, ou quem sabe a total compreensão do que está sendo exposto (Felipe, 2007; Galasso et al., 2018). Quando o docente percebe a necessidade de adaptar um material para a realidade de seu aluno surdo, isso é considerado pedagogicamente correto, haja vista que o professor compreendeu a verdadeira necessidade educacional para determinado caso (Alvez et al., 2010; Bomfim y Souza, 2010). São inúmeros os recursos didáticos trabalhados nas escolas brasileiras, sejam elas privadas ou públicas, para auxiliar e facilitar o desenvolvimento integral do aluno (Silva, 2014; Souza, 2007).

Souza (2007) considera recurso didático todo material utilizado como auxílio no ensino e na aprendizagem do conteúdo proposto, para ser aplicado pelo professor a seus alunos. De acordo com Felipe (2007), o material didático pode ser definido como recursos pedagógicos empregados na educação. Segundo o Novo Aurélio Século XXI: o Dicionário da Língua Portuguesa, o termo "recurso" significa ato ou efeito de recorrer, auxílio, ajuda, socorro, proteção. Já a palavra "pedagógico" está relacionada à pedagogia, ou seja, esta é definida como teoria e ciência da educação e do ensino, bem como, conjunto de doutrinas, princípios e métodos de educação e instrução que tendem a um objetivo prático (Ferreira, 1999).

Os materiais e equipamentos didáticos são todo e qualquer recurso utilizado em um procedimento de ensino, visando à estimulação do aluno e sua aproximação do conteúdo (Freitas, 2007). Portanto, pode-se definir que o recurso didático pedagógico é todo e qualquer material utilizado com a finalidade didática, voltada ao processo educacional (Silva, 2014; Souza, 2007). Os recursos didáticos são responsáveis pela parte sensorial ao estímulo dos alunos usando as novas tecnologias no processo educacional, e a classificação brasileira de recursos audiovisuais podem ser: a) visuais (álbum seriado, cartaz, exposição, fotografia, flanelógrafo, gráfico, gravura, mapa, modelos - mural, museu, objeto -, quadro de giz, quadro, transparência); b) auditivos (aparelho de som, disco, fita cassete, $C D$, rádio, CD-ROM); e c) audiovisuais (filme, dispositivo de filmes com som, cinema sonoro, televisão, videocassete, programa para computadores com som, aparelho de DVD, computador) (Freitas, 2007; Parra y Parra, 1985).

Os equipamentos e materiais didáticos são alguns recursos audiovisuais utilizados em sala de aula por educadores. É relevante salientar que esses recursos devem ser vistos como ferramentas de auxílio nas aulas de um professor em favor da educação respaldada na intenção do ensino e da aprendizagem de alunos (Freitas, 2007). Tais materiais devem ser utilizados com o objetivo específico e com metodologias adequadas e não como um passatempo recreativo (Galasso et al., 
2018; Granemann, 2017; Skliar, 1998).

As apresentações dos recursos didáticos nas aulas devem partir do intuito de intermediar os conteúdos abordados com o conhecimento dos alunos. A criação de materiais didáticos pedagógicos é uma alternativa para ser realizada com os alunos, pois despertam a curiosidade e a criatividade que estão escondidas neles e que podem facilitar o processo educacional, capazes de desenvolver informações para o ensino-aprendizagem e aguçar o desejo deles pelo conhecimento (Galasso et al., 2018; Thoma, 2012). "O recurso didático pode ser fundamental para que ocorra desenvolvimento cognitivo da criança, mas o recurso mais adequado, nem sempre será o visualmente mais bonito e nem o já construído" (Souza, 2007, p. 112).

O cuidado na seleção do material para uso nas aulas deve ter o planejamento e acompanhamento pedagógico, para que não se torne algo banal, sem importância para os alunos, não objetivando o ensino destes (Galasso et al., 2018; Souza, 2007).

Souza (2007) descreve que

O uso de materiais didáticos no ensino escolar, deve ser sempre acompanhado de uma reflexão pedagógica quanto a sua verdadeira utilidade no processo de ensino e de aprendizagem, para que se alcance o objetivo proposto. Não se pode perder em teorias, mas também não se deve utilizar qualquer recurso didático por si só sem objetivos claros ( $p$. 113).

O contato com o material concreto facilita a compreensão significativa dos educandos, pois 0 manuseio de objetos leva o aluno a formular questões mais significantes e a ter autonomia no que está sendo proposto (Martins, 2016; Skliar, 1998; Teske, 2012). Souza (2007) menciona que

Utiliza recursos didáticos no processo de ensino - aprendizagem é importante para que o aluno assimile o conteúdo trabalhado, desenvolvendo sua criatividade, coordenação motora e habilidade ao manusear objetos diversos que poderão ser usados pelo professor na aplicação de suas aulas (pp. 112-113).

De acordo com Freitas (2007), "consciência quanto ao uso racional dos materiais e equipamentos didáticos devem sofrer as influências positivas de uma educação voltada à formação de um sujeito crítico, autônomo, antenado com as demandas de sua época" (p. 129). Os recursos audiovisuais são exemplos de como o aluno pode ter o conhecimento, ao seu alcance, da sociedade em que vive, por meio de objetos que existem até mesmo em casa, como a televisão, o computador, entre outros. Assim, a criticidade pode se expandir, pois o aluno elabora as suas opiniões e indagações referentes ao tema abordado. 


\section{Recursos didáticos pedagógicos}

Segundo Freitas (2007), o importante é estabelecer "uma forma de comunicação com o aluno, para que ele possa se expressar e se fazer entender e, também entender o que os outros têm a manifestar. Por isso, aprender a língua de sinais é uma alternativa importante" (p. 124). Pois, sem ela, a comunicação com alunos surdos fica difícil, não surtindo resultados positivos para ambos os lados.

A partir da língua de sinais, os professores elaboram as aulas, as metodologias e os recursos que irão auxiliar pedagogicamente o trabalho com os alunos. E essas ações são definidas como "recursos especiais, materiais ou de comunicação que venham a facilitar os alunos com necessidades educacionais especiais a desenvolver o currículo escolar" (Ministério da Educação do Brasil, 2003, pp. 43-44).

São muitos os recursos disponibilizados por meios midiáticos. A partir desses exemplos, os professores produzem materiais de acordo com a realidade da criança atendida. Muitas vezes são criados por meio de recursos para ouvintes. Sendo que "as novas tecnologias da informação e da comunicação são recursos valiosíssimos quando se pretende sistematizar uma metodologia de trabalho com os alunos surdos" (Reis, 2012, p. 171).

Segundo a Política Nacional de Educação Especial na Perspectiva da Educação Inclusiva, em seu inciso VI (Diretrizes da Política Nacional de Educação Especial na Perspectiva da Educação) Inclusiva, para que as dificuldades encontradas pelos alunos com deficiência sejam eliminadas ou amenizadas é preciso que o atendimento educacional especializado (AEE) exerça sua função de identificar, elaborar e organizar metodologias e recursos pedagógicos de acordo com a necessidade educacional encontrada pelo estudante para que ele tenha mais compreensão e autonomia dentro e/ou fora do âmbito escolar (Ministério da Educação do Brasil, 2008).

Logo, o espaço físico do ambiente educacional é extremamente importante para as questões mencionadas no parágrafo anterior a fim de que as atividades com os alunos sejam preparadas para o atendimento. Têm-se como exemplo de espaços pedagógicos a quadra de esportes, o laboratório de ensino das ciências, a biblioteca da escola para além da sala de aula (Eiterer y Medeiros, 2010). O uso e exploração desses demais espaços da escola contribuem para o desenvolvimento e o ensino dos educandos (Nascimento et al., 2017).

No entanto, o principal e mais utilizado espaço pedagógico é a sala de aula (Klein y Lunardi, 2006; Lima, 2006; Lopes, 2007). O cuidado com esse local é importante, pois contém o perfil educacional da turma. "A sala de aula pode explicitar o processo de aprendizagem, bem como a linha pedagógica adotada pelo professor, uma vez que ali se encontram muitas informações sobre as atividades que estão sendo desenvolvidas" (Freitas, 2007, p. 55). A exploração do ambiente escolar deve ser levada em consideração para que o aluno ao longo de sua estada educativa sinta-se acolhido e tenha vontade de querer voltar a esse espaço para a busca de novas habilidades intelectuais, além da socialização com os colegas (Alvez et al., 2010; Lima et al., 2015).

Segundo Eiterer e Medeiros (2010), o que torna a ação, o material ou o espaço um recurso efetivamente pedagógico são os objetivos com que são utilizados, ou seja, a finalidade educativa e a 
maneira como, de fato, se constituem, de modo intencional em um meio de favorecimento do processo de ensino e aprendizagem.

\section{METODOLOGIA}

Este estudo é caracterizado como descritivo com abordagem qualitativa. O tipo e abordagem escolhidos e traçados conjuntamente se tornam pertinentes para o controle desta pesquisa, partindo da lógica empregada com a realidade educacional que perfez o foco planejado. O método descritivo é aquele que apresenta o propósito de analisar com mais precisão, fatos e/ou fenômenos com características próprias, por meio de observação, registro e correlações existenciais a fim de se verificarem possíveis conexões ou mesmo interferências (Gil, 2008; Leite, 2008). Já a abordagem metodológica qualitativa observa o dia a dia e tornou-se essencial para este manuscrito, pois ela objetiva aprofundar a compreensão de uma realidade (Creswell, 2007; Hernández Sampieri et al., 2013).

No que tange aos meios, foi utilizada a pesquisa de campo em que se verificaram os sujeitos da pesquisa em seu meio natural. "seu objetivo é observar, criticar a vida real, com base em teoria, para verificar como a teoria estudada se comporta na vida real. Confrontando a teoria na prática, permite responder ao problema e atingir os objetivos" (Michel, 2009, p. 42). Este estudo foi realizado em uma Escola Especial no Município de Parintins, AM. Utilizaram-se como técnica de coleta de dados a observação assistemática e entrevistas que foram respondidas por três professores, um docente de sala de aula, um da brinquedoteca e um do AEE. As questões que nortearam o questionário se focaram em uma aluna surda em relação a processos educacionais, o que inclui a alfabetização.

\section{Apresentação e discussão dos dados}

Segundo o relato dos professores que atuam com a criança surda, ela demonstrava nos primeiros contatos (com docentes, alunos e funcionários) um pouco de receio por não saber como lidar com outras pessoas que não faziam parte de seu ciclo familiar. Ao longo da estada educacional (processo alfabetizador), a aluna começou a se socializar com os colegas gesticulando ou apontando os objetos o que gostaria de obter ou desejava. A partir desses pequenos gestos, os professores deram início à alfabetização da aluna quando observaram que ela estava cada vez mais se desenvolvendo, principalmente porque estava tendo o contato com outras crianças surdas no ambiente escolar. Notou-se também que os recursos didáticos pedagógicos influenciaram positivamente no processo da alfabetização, pois potencializaram o desenvolvimento cognitivo e social da aluna surda. Os proponentes deste estudo observaram a aluna surda em três salas, nas quais frequentava, sendo: a) sala de aula (13h às $15 \mathrm{~h} 30$ na segunda-feira; $13 \mathrm{~h}$ às $17 \mathrm{~h}$ de terça-feira a quinta-feira; $15 \mathrm{~h} 45$ às $17 \mathrm{~h}$ na sexta-feira); b) sala de atendimento educacional especializado (13h às $15 \mathrm{~h} 30$ na sexta-feira); c) brinquedoteca ( $15 \mathrm{~h} 45$ às $17 \mathrm{~h}$ na segunda-feira).

A partir das sete questões a seguir, evidencia-se como os professores notaram o 
desenvolvimento da aluna ao longo do processo alfabetizador por meio dos recursos pedagógicos e de como o espaço em que a aluna utiliza com os demais colegas ouvintes são explorados para esse processo na abordagem bilíngue, além da influência e participação familiar.

Questão 1: Em sua opinião, em que os recursos pedagógicos podem influenciar no processo de alfabetização da criança surda?

tanto os recursos pedagógicos construídos pelo professor como os já fabricados devem ser utilizados como ferramentas para potencializar as habilidades cognitivas das crianças surdas (Professor da sala de aula).

todos os recursos lúdicos sendo utilizados pelo educador com linguagem adequada para a criança com surdez contribui para a sua aprendizagem (Professor do AEE).

o último atendimento realizado na brinquedoteca, com a turma, foi a confecção do presépio de Natal... Toda essa representação simbólica para o concreto e a comparação auxilia a criança a organizar seu pensamento para que ela possa contextualizar com o mundo que a cerca. E tenha $o$ mesmo direito que uma criança ouvinte. (Professor da brinquedoteca).

O professor da sala de aula afirma somente que o desenvolvimento cognitivo das crianças surdas é estimulado por meio dos recursos didáticos confeccionados ou fabricados. O professor do AEE diz que a linguagem adequada contribui para a criança surda, porém, a definição de linguagem é "tendida num sentindo mais amplo, ou seja, incluindo qualquer tipo de manifestação de intenção comunicativa" (Quadros, 2004, p. 8). Logo, pode ser entendida como a linguagem de um animal ou expressões das pessoas como a mímica ou gestos. Por isso, define-se a língua como "um fato social, ou seja, um sistema coletivo de uma determinada comunidade linguística. A língua é a expressão linguística que é tecida em meio a trocas sociais, culturais e políticas" (Quadros, 2004, pp. 7-8). Nesse sentido é que a fala do professor se encaixa corretamente.

Já o professor da brinquedoteca afirma que por meio de materiais concretos os alunos podem compreender as atividades, pois passam pelo simbolismo até a comparação em que a aluna formula seus pensamentos refletindo sobre a sociedade dos ouvintes e surdos.

Questão 2: Você utiliza materiais pedagógicos em suas aulas? Quais?

Sim, utilizo recursos pedagógicos de baixo padrão que são todos os recursos produzidos pelo professor. Também, recursos pedagógicos de alto padrão que são objetos de aprendizagem por meio do uso de multimídia no notebook, acesso à internet na sala de aula para trabalhar os mais diversos conceitos como geografia, história, arte (Professor da sala de aula).

Sim, uso materiais concretos diversificados, sendo trabalhados na metodologia bilíngue (Professor do AEE). 
Sim, utilizo alfabeto manual de língua portuguesa, alfabeto e números em LIBRAS, mímica, dramatização, desenhos, ilustrações, fotografias, tecnologias de informação e comunicação, como vídeos e literatura infantil, jogo da memória, jogos de associação, literatura impressa na escrita em sinais, sequência didática, quebra-cabeça, livros, revistas (Professor da brinquedoteca).

O professor de sala de aula classifica os recursos pedagógicos como de alto e baixo padrão aqueles que ele utiliza em sala com os alunos. Esses objetos de aprendizagem contribuem demasiadamente com o desenvolvimento da criança surda. Para tanto, a utilização desses recursos didáticos se torna muito mais visuoespacial em relação a docentes que utilizam unicamente a língua de sinais e o quadro branco.

Já o professor de AEE utiliza materiais concretos, assim como os demais, pois contribuem com a aprendizagem efetiva. Jogos, como tabuleiro, cartazes e livros bilíngues auxiliam nesse processo (Felipe, 2007).

$\mathrm{Na}$ brinquedoteca, o professor destaca os mais diversos jogos, brinquedos, multimídias utilizados com os alunos, fatores importantes quando são usados corretamente na educação dos surdos (Lopes, 2007; Sá, 2006).

Questão 3: O espaço escolar oferecido para suas aulas é um ambiente favorável para a aprendizagem de alunos surdos?

Sim, é importante saber que o surdo deve estar inserido em uma abordagem educacional bilíngue onde aspectos do desenvolvimento de sua língua materna e o estudo da língua portuguesa, na modalidade escrita, devem caminhar juntas. Isso é proporcionado na alfabetização na escola. $O$ desenvolvimento desses aspectos está ligado a outros serviços da escola, como sala de recursos, brinquedoteca, educação física, teatro (Professor da sala de aula).

Sim, pois os alunos participam e interagem em todos os locais da escola, levando-os ao desenvolvimento, participação e socialização. (Professor do AEE).

Sim, o espaço escolar para as aulas é um ambiente favorável à aprendizagem de pessoas surdas. Pois os conteúdos abordados em sala de aula são contextualizados de forma lúdica na brinquedoteca, aprendendo a ler os sinais, trabalhos de socialização em dupla com surdo e ouvinte, em grupo com ouvinte, surdo e ouvinte, brinquedos, produção de literatura infantil em sinais, relatos dos alunos e professores, dicionário em LIBRAS. (Professor da brinquedoteca).

Os professores concordam que o espaço escolar oferecido aos alunos é correspondido 
satisfatoriamente no processo educacional bilíngue, a participação e socialização da criança com os demais alunos surdos e ouvintes da escola contribuem para o ensino-aprendizagem. Esses fatores contribuíram com o desenvolvimento da aluna surda em aspectos múltiplos. "Uma aula bem planejada, preparada com recursos didáticos adequados, começa com uma organização funcional e harmônica do espaço onde ela vai ocorrer" (Freitas, 2007, p. 54). Um dos professores destaca que a brinquedoteca é um espaço que contribui significativamente para a educação. As atividades realizadas por outros professores - em outros espaços - são trabalhadas com metodologias diferentes nas dependências da brinquedoteca e isso não deixa de contribuir com o professor de sala de aula.

Questão 4: Como você observa a participação da família no processo de alfabetização do aluno surdo nas atividades propostas?

a participação da família é muito tímida! A compreensão dessa participação deve ser analisada em um contexto histórico e cultural de como a escola vem construindo essa experiência. As famílias que têm surdos, infelizmente, não conseguem acompanhar o processo de educação escolar em função de não terem conhecimento mínimo para se comunicar com os filhos surdos. (Professor da sala de aula).

Ainda falta a participação concreta da família. Pois é ela que se constitui como principal instituição facilitadora para a comunicação do nosso aluno. Apesar de a escola oferecer, o ano todo, oficinas de LIBRAS, é notório o desinteresse familiar em participar e prestigiar desse momento pedagógico em que se aprende a LIBRAS. (Professor do AEE).

A família ainda está em processo de alfabetização em língua de sinais. Mas, busca pouco os professores para auxiliá-los. (Professor da brinquedoteca).

A escola oferece aos pais de alunos e demais familiares cursos de LIBRAS para que possam ter mais contato com a língua de sinais, para contribuírem com a educação e comunicação com as crianças surdas em casa, mas não são todas as famílias que têm o interesse nessa oferta. Os professores em contato corriqueiro com a família da aluna tentam contribuir e incentivar a conhecer a língua de sinais a fim de que possam transmitir valores à criança e, também, melhores formas de comunicação entre todos os familiares, mas nem sempre isso é conquistado.

Questão 5: A LIBRAS como componente essencial em conjunto com recursos pedagógicos é bem aceita pela aluna no processo de alfabetização?

Sim, qualquer recurso pedagógico construído para mediar o desenvolvimento global da criança surda deve estar acompanhada dos recursos da LIBRAS (Professor da sala de aula).

Claro que sim, pois é por meio dela que se comunica e interage com os 
demais colegas e seu ambiente escolar (Professor do AEE).

Sim, pois apresenta interesse em responder suas atividades com êxito. (Professor da brinquedoteca).

Em conversas informais com os professores, disseram que a aluna surda quando chegava ao ambiente escolar não sabia como se expressar ou comunicar com os outros alunos surdos e ouvintes e que a LIBRAS foi extremamente importante para esse contato com os colegas e professores da escola. "O processo de alfabetização vai sendo delineado com base neste processo de descoberta da própria língua e de relações expressadas por meio da língua" (Quadros y Schmiedt, 2006, p. 28).

As respostas positivas com relação à aceitação da aluna só reforçam a ideia de que a língua materna dos surdos contribuiu para o desenvolvimento durante a alfabetização da aluna, e que a compreensão e expressão dela, por meio dos recursos didático-pedagógicos, influenciaram na aquisição da língua de sinais. Menciona-se, ainda, que o uso da língua de sinais é muito mais que inserir sinais isolados dentro de atividades (Granemann, 2017; Ochiuto y Constâncio, 2018). "Sua aquisição requer muito mais que exercícios; requer contato com usuários da língua, requer o outro que introduza a criança no mundo conceitual pela vivência de uso da língua" (Agria y Vieira, 2013, p. 114 , cursiva del autor).

Questão 6: Que análise você faz sobre o desenvolvimento da aprendizagem da aluna desde seu ingresso até o atual momento? considero que houve muitos avanços na relação interpessoal com os colegas ouvintes e maior ganho no vocabulário da LIBRAS. Na modalidade escrita, iniciou-se um processo de desenvolvimento e aquisição dessa habilidade que precisa ser potencializado nas etapas posteriores (Professor da sala de aula).

um bom desempenho escolar. Apesar que eu tenho apenas um dia na semana para o seu atendimento (Professor do AEE).

no início apresentava dificuldades, mas, no decorrer do ano letivo, apresentou avanços significativos na aquisição de sua língua materna e na língua portuguesa. (Professor da brinquedoteca).

O professor de sala de aula comenta sobre o desempenho e desenvolvimento da aluna surda, na questão interpessoal, pois ela não tinha contato com outras crianças surdas, somente com os familiares, que são todos ouvintes, e o ambiente escolar proporcionou esse desenvolvimento principalmente pelo contato com a LIBRAS. Em relação à língua portuguesa, a criança está adquirindo aos poucos, em processos lentos, pois, muitas vezes, ela se irrita por não conseguir responder à proposta dos conteúdos. No entanto, o professor a estimula nesse processo de aquisição da língua portuguesa, e as tecnologias da informação e comunicação são exemplos de recursos usados em sala com os alunos. Uma vez por semana, durante o ano letivo, os professores de AEE e brinquedoteca tiveram o contato com a aluna. Essa única vez por semana é justificada pela demanda 
de alunos a serem atendidos na escola, no entanto, isso foi o suficiente para descrever os avanços adquiridos ao longo do percurso temporal de estada com a aluna surda.

Questão 7: Quais foram os maiores desafios para o processo de alfabetização da aluna surda?

A modalidade escrita da língua portuguesa é uma das mais dificultosa que acompanha o professor em todas as etapas, principalmente na alfabetização. Como desafio para o professor, é ter habilidade e conhecimentos na língua materna do surdo para fazer desenvolver na criança a experiência da abordagem bilíngue (Professor da sala de aula).

Não há desafios maiores ou menores da parte pedagógica na sala de recursos em LIBRAS e nem no ambiente escolar. Observo que ela interage, participa, tem criatividade em suas atividades (Professor do AEE).

O maior desafio foi ser inserida na escola e depois na sala de aula. Aos poucos, ela foi compreendendo que existia uma comunidade de surdos e ouvintes, que poderia ajudá-la (Professor da brinquedoteca).

Pode-se observar que o professor de sala de aula cita a dificuldade de ensinar a aluna na modalidade escrita na língua portuguesa nessa etapa da escolarização, pois o docente deve ter o cuidado e conhecimento necessário para expor ou abordar um tema para a criança surda, haja vista suas especificidades educacionais. Já a professora do AEE diz que não teve dificuldades no ensino em LIBRAS, que a aluna obteve com êxito as competências exigidas para seu processo de alfabetização, assim como a professora da brinquedoteca, que diz que a aluna percebeu que no ambiente escolar a comunidade surda e ouvinte poderia lhe ajudar em seu processo de alfabetização e socialização.

\section{CONSIDERAÇÕES FINAIS}

Considera-se que o objetivo proposto foi atingido de forma eficaz ao longo do fluxo textual. A contribuição de recursos pedagógicos utilizados em ambiente educacional teve resultados positivos no ensino da aluna surda, observando as alternativas de apoio pedagógico do professor para o processo de aprendizagem formal dos alunos.

Menciona-se que este estudo forneceu informações relevantes a serem observadas no processo educacional da criança surda por meio de recursos didático-pedagógicos que são essenciais para a etapa de alfabetização e letramento. Observou-se que as tecnologias da informação e comunicação são ferramentas importantes nesse processo, pois contribuem com o ensino e auxiliam o professor na prática docente em favor da aprendizagem dos discentes. Essas mesmas tecnologias apresentam-se como instrumentos facilitadores que integram, estimulam e influenciam aspectos pessoais, sociais e educacionais. Levam-se também em consideração os demais recursos pedagógicos concretos utilizados por meio de jogos, brincadeiras em grupos, entre 
outros, que contribuem de forma paralela, mas potencialmente viáveis quando o que se está em jogo é a estimulação de processos educacionais.

A educação bilíngue (LIBRAS e português na modalidade escrita) para surdos oferecida na escola é um grande desafio para que os professores, especialmente no que tange a aspectos gramaticais de uma estrutura que não atende a perspectiva visiospacial própria da pessoa surda. No entanto, o contato com a língua de sinais, por ser uma língua espontânea, contribui muito com o processo de alfabetização escolar. Assim, a utilização dos recursos didáticos só tem a enriquecer o desenvolvimento linguístico da aluna surda.

Acrescenta-se, ainda, que o espaço da unidade escolar corresponde às expectativas de atender a criança surda no desenvolvimento em seus aspectos sociais e educacionais, fazendo com que ela explore e o utilize de forma mais conveniente. Portanto, nota-se que os recursos didáticopedagógicos utilizados no ambiente escolar e no processo educacional bilíngue influenciam o aprendizado da criança surda em seu desenvolvimento cognitivo e nos processos interpessoais. Tal característica faz com que a criança interaja, participe das atividades propostas e corresponda aos conteúdos abordados em sala de aula.

\section{REFERÊNCIAS}

Agria, A. C. Q., y Vieira, C. R. (2013). Conceito de língua materna, primeira língua e segunda língua e suas implicações no campo da surdez. En N. A. Albres y S. L. G. Neves (Org.), Libras em estudo: política lingüística (pp. 105-123). FENEIS. https://issuu.com/diaslibras/docs/albres_e_neves_2013_libras_pol_tic

Almeida, D. L., y Lacerda, C. B. F. (2019). Português como segunda língua: a escrita de surdos em aprendizagem coletiva. Trabalhos em Linguística Aplicada, 58(2), 899-917. https://www.scielo.br/pdf/tla/v58n2/0103-1813-tla-58-02-0899.pdf

Alvez, C. B., Ferreira, J. P., y Damázio, M. M. (2010). A educação especial na perspectiva da inclusão escolar: abordagem bilíngue na escolarização de pessoas com surdez. Ed. MEC/SEESP. https://www.editorasolucao.com.br/media/downloads/prefeitura-de-cerquilho-sp-2019professor-de-educacao-basica-i-abordagem-bilingue-na-escolarizacao-de-pessoas-comsurdez-141ma.pdf

Avelar, T. F., y Freitas, K. P. S. (2016). A importância do português como segunda língua na formação do aluno surdo. Sinalizar, 1(1), 12-24. https://revistas.ufg.br/revsinal/article/download/36688/20219

Barros, A. L. E. C., Nascimento, J. R., y Borges, J. P. O. (2017). Aquisição da língua portuguesa pelo surdo. InterLetras, 6(25), 1-10. https://www.unigran.br/dourados/interletras/ed_anteriores/n25/conteudo/artigos/9.pdf

Bomfim, R. O., y Souza, A. P. R. (2010). Surdez, mediação e linguagem na escola. Psicologia USP, 21(2), 417-437. https://www.scielo.br/pdf/pusp/v21n2/v21n2a10.pdf

Borges, A. S., Rocha, J. S., y Justi, J. (2017). Inclusão educacional do aluno surdo: uma perspectiva social e reflexiva. Professare, 6(3), 67-86. 
http://periodicos.uniarp.edu.br/index.php/professare/article/download/1308/734

Creswell, J. W. (2007). Projeto de pesquisa: métodos qualitativo, quantitativo e misto (2ํe. ed. Artmed. Decreto n. 5.626 de 22 de dezembro de 2005. (2005). Regulamenta a Lei n. 10.436, de 24 de abril de 2002, que dispõe sobre a Língua Brasileira de Sinais - Libras, e o art. 18 da Lei n. 10.098, de 19 de dezembro de 2000. Diário Oficial [da] República Federativa do Brasil. http://www.planalto.gov.br/ccivil_03/_ato2004-2006/2005/decreto/d5626.htm

Eiterer, C. L., y Medeiros, Z. (2010). Recursos pedagógicos En D. A. Oliveira, A. M. C. Duarte y L. M. F. Vieira (Org.), Dicionário: trabalho, profissão e condição docente. Ed. UFMG/Faculdade de Educação, Belo Horizonte. http://www.gestrado.net.br/pdf/155.pdf

Ellis, R. (1997). Second language acquisition in context. Oxford University Press.

Felipe, T. A. (2007). Libras em contexto: curso básico, livro do estudante ( $8^{\circ}$ ed.). Walprint.

Fernandes, S., y Moreira, L. C. (2009). Desdobramentos político-pedagógicos do bilinguismo para surdos: reflexões e encaminhamentos. Educação Especial, 22(34), 225-236. http://www.educadores.diaadia.pr.gov.br/arquivos/File/artigos_edespecial/desdobramentos.pd $f$

Fernandes, S., y Moreira, L. C. (2014). Políticas de educação bilíngue para surdos: o contexto brasileiro. Educar em Revista, (2/2014), 51-69. https://www.scielo.br/pdf/er/nspe-2/05.pdf

Ferreira, A. B. H. (1999). Novo Aurélio século XXI: o dicionário da língua portuguesa (3ํed.). totalmente revista e ampliada. Nova Fronteira.

Ferreira, L. (2010). Por uma gramática de línguas de sinais ( $2^{\circ}$ ed.). Tempo Brasileiro, Rio de Janeiro.

Freitas, O. (2007). Equipamentos e materiais didáticos. Ed. Universidade de Brasília. http://portal.mec.gov.br/seb/arquivos/pdf/profunc/equipamentos.pdf

Galasso, B. J. B., Souza, L. M. R., Severino, R. M., Lima, R. G., y Teixeira, D. E. (2018). Processo de produção de materiais didáticos bilíngues do Instituto Nacional de Educação de Surdos.

Revista Brasileira de Educação Especial, 24(1), 59-72.

https://www.scielo.br/j/rbee/a/R8nwGtrSrb3LdF9BvbxNZLt/?format=pdf\&lang=pt

Gil, A. C. (2008). Métodos e técnicas de pesquisa social (6ºed.). Atllas.

Granemann, J. L. (2017). Língua Brasileira de Sinais - Libras como L1 para estudantes surdos nos anos iniciais do ensino fundamental. REVELLI - Revista de Educação, Linguagem e Literatura, 9(2), 270-282. https://www.revista.ueg.br/index.php/revelli/article/view/5894/4506

Hernández Sampieri, R., Collado, C. F., y Lucio, M. P. B. (2013). Metodologia de pesquisa. Traduccion Daisy Vaz de Moraes (5e․). Penso.

Justi, J., Justi, E. B. L. J., Justi, J., Fonseca, J. L. P., y Oliveira, H. X. (2017). Estudo reflexivo frente à inclusão educacional da pessoa com necessidades especiais: uma perspectiva pedagógica [Artículo del congreso]. Congreso Interdisciplinar de Pesquisa, Iniciação Científica e Extensão Universitária do Centro Universitário Metodista Izabela Hendrix, Belo Horizonte, MG, Brasil. http://izabelahendrix.edu.br/pesquisa/anais/arquivo-2017/estudo-reflexivo-frente-a-inclusaoeducacional-da-pessoa-com-necessidades-especiais-uma-perspectivapedagogica/@@download/file/Anais.2017.p.\%20986.pdf

Klein, M., y Lunardi, M. L. (2006). Surdez: um território de fronteiras. Educação Temática Digital, 7(2), 
14-23. https://periodicos.sbu.unicamp.br/ojs/index.php/etd/article/view/787/802

Lacerda, C. B. F., y Santos, L. F. (2012). O surdo e o atendimento educacional especial: onde se aprende a Libras? Em ambiente natural ou artificial? En: L. C. Silva, y M. P. Mourão (Org.), Atendimento educacional especializado para alunos surdos (Vol. 2, pp. 141-149). EDUFU. http://www.edufu.ufu.br/sites/edufu.ufu.br/files/ebook_atendimento_educacional_para_surdos_2013_0.pdf

Lacerda, C. B. F., Albres, N. A., y Drago, S. L. S. (2013). Política para uma educação bilíngue e inclusiva a alunos surdos no município de São Paulo. Educação e Pesquisa, 39(1), 65-80. https://www.scielo.br/pdf/ep/v39n1/v39n1a05.pdf

Lane, H. (1992). A máscara da benevolência: a comunidade surda amordaçada. Instituto Piaget.

Lei n. 10.436 de 24 de abril de 2002. (2002). Dispõe sobre a Língua Brasileira de Sinais - Libras e dá outras providências. Diário Oficial [da] República Federativa do Brasil. http://www.planalto.gov.br/ccivil_03/leis/2002/l10436.htm

Leite, F. T. (2008). Metodologia científica: métodos e técnicas de pesquisa: monografias, dissertações, teses e livros ( $3^{\circ}$ ed.). Ideias e Letras.

Lima, C. M., Sampaio, C. S. R., y Ribeiro, T. (2015). Apontamentos sobre a educação de surdos: aprendizagens no encontro com a surdez. Espaço, (43), 92-115. http://www.ines.gov.br/seer/index.php/revista-espaco/article/download/7/20

Lima, P. A. (2006). Educação Inclusiva e igualdade social. Avercamp.

Lodi, A. C. B. (2013a). Ensino da língua portuguesa como segunda língua para surdos: impacto na educação básica. En C. B. F., Lacerda y L. F. Santos (Org.), Tenho um aluno surdo, e agora? Introdução à Libras e educação de surdos (pp. 165-183). EDUFSCar.

Lodi, A. C. B. (2013b). Educação bilíngue para surdos e inclusão segundo a Política Nacional de Educação Especial e o Decreto n. 5.626/05. Educação e Pesquisa, 39(1), 49-63. https://www.scielo.br/pdf/ep/v39n1/v39n1a04.pdf

Lodi, A. C. B., Bortolotti, E. C., y Cavalmoreti, M. J. Z. (2004). Letramentos de surdos: práticas sociais de linguagem entre duas línguas/culturas. Bakhtiniana: Revista de Estudos do Discurso, 9(2), 131-149. https://www.scielo.br/pdf/bak/v9n2/a09v9n2.pdf

Lopes, M. C. (2007). Surdez \& educação. Autêntica.

Martins, V. R. O. (2016). Educação de surdos e proposta bilíngue: ativação de novos saberes sob a ótica da filosofia da diferença. Educação \& Realidade, 41(3), 713-729. https://www.scielo.br/pdf/edreal/v41n3/2175-6236-edreal-41-03-00713.pdf

Michel, M. H. (2009). Metodologia e pesquisa científica em ciências sociais (2ํe․). Atlas.

Ministério da Educação do Brasil. (2003). Estratégias para educação de alunos com necessidades educacionais especiais. Ed. MEC/SEESP. http://portal.mec.gov.br/seesp/arquivos/pdf/serie4.pdf

Ministério da Educação do Brasil. (2008). Política nacional de educação especial na perspectiva da educação inclusiva. Ed. MEC/SEESP. http://portal.mec.gov.br/arquivos/pdf/politicaeducespecial.pdf

Mota, M. B. (2008). Aquisição de segunda língua. [Monografía de licenciatura, Universidade Federal 
de Santa Catarina]. Repositório Institucional da UFSC.

http://www.libras.ufsc.br/colecaoLetrasLibras/eixoFormacaoEspecifica/aquisicaoSegundaLing ua/assets/630/Texto-base_disciplina_AQUISICAOL2.pdf

Nascimento, S. P. F., y Costa, M. R. (2014). Movimentos surdos e os fundamentos e metas da escola bilíngue de surdos: contribuições ao debate institucional. Educar em Revista, 30(2), 159-178. https://revistas.ufpr.br/educar/article/download/37021/23118

Nascimento, T. S. B., Silva, E. F., Justi, J., y Freitas, H. O. G. (2017). Desafios e práticas da educação inclusiva no contexto institucional: uma reflexão pedagógica. En E. C. P. Manchope, A. Araújo, K. M. B. Sales, Laurence D. Colvara, N. L. P. Fortes, P. S. Wolff, S. C. T. Luz y V. L. R. Maquêa (Org.), Relato de experiências exitosas das IES: formação do docente do ensino superior, assistência estudantil e assistência pedagógica (pp. 329-343). Ed. Universidade Estadual do Oeste do Paraná. https://docplayer.com.br/75188501-Editora-da-universidadeestadual-do-oeste-do-parana-edunioeste.html

Ochiuto, E. F. A. S., y Constâncio, R. F. J. (2018). A aquisição da LIBRAS como L1 e da língua portuguesa como L2 para surdos: uma visão funcionalista. Polifonia, 25(39.2), 183-302. http://periodicoscientificos.ufmt.br/ojs/index.php/polifonia/article/download/7421/4889

Oliveira, H. X., Justi, J., y Antunes, J. M. (2019). Caracterização de processos inclusivos em ambiente educacional. En Editora Poisson (Org.), Educação no século XXI, especial, inclusiva (Vol. 40, pp. 13-26). Poisson. https://www.poisson.com.br/livros/educacao/volume40/

Parra, N., y Parra, I. C. C. (1985). Técnicas audiovisuais de educação (5o ed.). Pioneira.

Quadros, R. M. (1997). Educação de surdos: a aquisição da linguagem. Artmed.

Quadros, R. M. (2004). O tradutor e intérprete de língua brasileira de sinais e língua portuguesa. Ed. MEC/SEESP.

Quadros, R. M., y Schmiedt, M. L. (2006). Idéias para ensinar português para alunos surdos. Ed. MEC/SEESP. http://portal.mec.gov.br/seesp/arquivos/pdf/port_surdos.pdf

Rafaeli, K. S. C., y Silveira, M. D. D. (2009). Caderno de estudos: libras. Asselvi. http://www.servi.adm.br/arquivo/caderno_de_libras.pdf

Reis, F. (2012). Pensando a metodologia de ensino para surdos no AEE. En L. C. Silva y M. P. Mourão (Org.), Atendimento educacional especializado para alunos surdos (Vol. 2, pp. 171174). EDUFU. http://www.edufu.ufu.br/sites/edufu.ufu.br/files/ebook_atendimento_educacional_para_surdos_2013_0.pdf

Sá, N. R. L. (2006). Cultura, poder e educação de surdos. Paulinas.

Sánchez, C. M. (1990). La increible y triste historia de la sordera. Ceprosord.

Senna, L. A. G. (2019). O Estatuto Linguístico da Língua Brasileira de Sinais e a superação do estigma na educação de surdos. Revista Brasileira de Educação Especial, 25(3), 487-500. https://www.scielo.br/pdf/rbee/v25n3/1413-6538-rbee-25-03-0487.pdf

Silva, C. C., y Justi, J. (2018). Desafios para a efetivação da educação inclusiva da pessoa surda. Revista Caribeña de Ciencias Sociales. https://www.eumed.net/rev/caribe/2018/11/educacaoinclusiva-pessoasurda.html

Silva, G. M. (2014). O processo de ensino-aprendizagem da leitura em uma turma de alunos surdos: 
uma análise das interações mediadas pela Libras. Revista Brasileira de Linguística Aplicada, 14(4), 905-933. https://www.scielo.br/pdf/rbla/v14n4/v14n4a07.pdf

Silva, R. C. D., y Martins, S. E. S. O. (2020). Surdez e alteridade: "o encontro entre o tilintar das vozes e o tremular das mãos". Pro-Posições, 31(e20170167), 1-23. https://www.scielo.br/pdf/pp/v31/1980-6248-pp-31-e20170167.pdf

Skliar, C. B. (1998). Os estudos surdos em educação: problematizando a normalidade. En C. B. Skliar (Org.), A surdez: um olhar sobre as diferenças (pp. 7-31). Mediação.

Sousa, A. N. (2018). O desenvolvimento da escrita de surdos em português (segunda língua) e inglês (terceira língua). semelhanças e diferenças. Revista Brasileira de Linguística Aplicada, 18(4), 853-886. https://www.scielo.br/pdf/rbla/v18n4/1984-6398-rbla-18-04-853.pdf

Souza, S. E. (2007). O uso de recursos didáticos no ensino escolar. Arquivo Mudi, (11), 110-114. Suplemento 2. http://www.dma.ufv.br/downloads/MAT\%20103/2015II/slides/Rec\%20Didaticos\%20-\%20MAT\%20103\%20-\%202015-II.pdf

Teixeira, D. S., Andrade, A. O., Justi, J., y Serrão, V. A. S. (2020). Reflexões em torno da educação de surdos. En Editora Poisson (Org.), Série educar: educação especial (Vol. 2, pp. 7-14). Poisson. https://www.poisson.com.br/livros/serie_educar/volume2/

Teske, O. (2012). Surdos: um debate sobre letramento e minorias. En A. C. B. Lodi, A. D. B. Melo y E. Fernandes (Org.), Letramento, bilinguismo e educação de surdos (pp. 25-48). Mediação.

Thoma, A. S. (2012). Representações sobre os surdos, comunidades, cultura e movimento surdo. En M. C. Lopes (Org.), Cultura surda \& Libras (pp. 154-180). Ed. Unisinos.

Thoma, A. S. (2016). Educação bilíngue nas políticas educacionais e linguísticas para surdos: discursos e estratégias de governamento. Educação \& Realidade, 41(3), 755-775. https://www.scielo.br/pdf/edreal/v41n3/2175-6236-edreal-41-03-00755.pdf

Vieira, M. I. I. (2017). A atuação do intérprete educacional da LIBRAS nas escolas de ensino fundamental de Limoeiro do Norte-CE. [Tesis de maestria, Universidade Estadual do Ceará]. Repositório Institucional da UECE. http://www.uece.br/maie/dmdocuments/dissertacao_maria_izalete_inacio_vieira.pdf

Williams, S., y Hammarberg, B. (1998). Language switches in L3 production: Implications for a polyglot speaking model. Applied Linguistics, 19(3), 295-333.

Woodward, J. (1972). Implications for sociolinguistic research among the deaf. Sign Language Studies, (1), 1-7. 